\title{
Hepatitis B virus $X$ protein promotes renal epithelial-mesenchymal transition in human renal proximal tubule epithelial cells through the activation of NF-кB
}

\author{
MEI LI* , LIPING HU* , FENGXIN ZHU, ZHANGMEI ZHOU, JIANWEI TIAN and JUN AI \\ Division of Nephrology, Nanfang Hospital, Southern Medical University, Guangzhou, Guangdong 510515, P.R. China
}

Received November 2, 2015; Accepted May 31, 2016

DOI: $10.3892 /$ ijmm.2016.2637

\begin{abstract}
Hepatitis B virus (HBV)-associated glomerulonephritis is the most common extra-hepatic disorder occurring with hepatitis B virus infection. In the present study, we hypothesized that $\mathrm{HBV} \mathrm{X}$ protein $(\mathrm{HBx})$ may play a critical role in renal interstitial fibrosis, as $\mathrm{HBx}$ has been shown to induce epithelial-mesenchymal transition (EMT) in renal cells. For this purpose, we successfully transfected HBx plasmid into human renal proximal tubule epithelial cells (HK-2 cells). We found that transfection with $\mathrm{HBx}$ plasmid significantly downregulated E-cadherin expression and upregulated $\alpha$-smooth muscle actin, collagen I and fibronectin expression in a time- and concentration-dependent manner (at the lower concentrations and earlier time points). $\mathrm{HBx}$ also increased nuclear factor $-\kappa \mathrm{B}(\mathrm{NF}-\kappa \mathrm{B})$ phosphorylation in a time- and concentration-dependent manner (again at the lower concentrations and earlier time points); however, it did not alter the phosphorylation of Smad2, Smad3, p38, phosphoinositide 3-kinase (PI3K) or extracellular signal-regulated kinase (ERK). Thus, the findings of this study demonstrate that HBx promotes EMT in renal HK-2 cells, and the potential underlying mechanisms may involve the activation of the $\mathrm{NF}-\kappa \mathrm{B}$ signaling pathway.
\end{abstract}

\section{Introduction}

Chronic infection with hepatitis B virus (HBV) not only greatly increases the risk of developing hepatic fibrosis, hepatic sclerosis and hepatocellular carcinoma, but is also associated with damage to several other extra-hepatic organs (1). Many types of extra-hepatic manifestations have been observed in patients

Correspondence to: Dr Jun Ai, Division of Nephrology, Nanfang Hospital, Southern Medical University, 1838 North Guangzhou Ave, Guangzhou, Guangdong 510515, P.R. China

E-mail: aij1980@163.com

*Contributed equally

Key words: hepatitis $\mathrm{B}$ virus $\mathrm{X}$ protein, renal epithelial-mesenchymal transition, nuclear factor- $\kappa \mathrm{B}$ phosphorylation, HK-2 cells, transforming growth factor- $\beta 1$ with both acute and chronic hepatitis with HBV infection (1). Renal involvement is among the most common extra-hepatic manifestation and usually manifests in the form of immune complex-mediated nephropathy, such as membranous glomerulonephritis, membranoproliferative glomerulonephritis and immunoglobulin A nephropathy (2-4).

To date, tubular and interstitial damage has attracted much attention, although glomerular damage has been proven to be the main pathological characteristic of HBV-associated glomerulonephritis (HBV-GN). It has been reported that inflammatory cell infiltration and tubulointerstitial fibrosis are observed in patients with HBV-GN, and HBV DNA and RNA have been identified in renal tubular cells. Thus, tubulointerstitial damage may play an important role in $\operatorname{HBV}-\mathrm{GN}(5,6)$.

The HBV X protein $(\mathrm{HBx})$, a $17-\mathrm{kDa}$ protein, is the smallest open reading frame in the HBV genome, and it is located at 1374-1838 bp of the HBV genome. The overall length is 435 to $462 \mathrm{bp}$, and the code length is of a protein containing 154 amino acids. HBx is a multifunctional protein and it activates multiple cellular signal transduction pathways and regulates apoptosis. A number of studies have suggested that $\mathrm{HBx}$ activates the nuclear factor- $\kappa \mathrm{B}(\mathrm{NF}-\mathrm{\kappa} \mathrm{B})$, Janus kinase/signal transducers and activators of transcription (JAK/STAT), Ras-Raf-mitogenactivated protein kinase (MAPK), p38 MAPK, c-Jun $\mathrm{N}$-terminal kinase (JNK), phosphoinositide 3-kinase (PI3K) and the Src tyrosine kinase signaling pathways (7-11) to induce host cell apoptosis.

Recently, HBx was detected in renal tissues, mainly in tubular epithelial cells (7). Wang et al reported that HBx induced epithelial-mesenchymal transition (EMT) and immunity disorder in renal tubule epithelial cells through the Notch1 pathway (12). However, the transforming growth factor- $\beta$ (TGF- $\beta)(13,14)$ pathway plays an important role in renal EMT, and its downstream factors, such as Smads, p38, extracellular signal-regulated kinase (ERK), PI3K and NF- $\kappa$ B also play an important role in EMT. Thus, in the present study, we aimed to determine the role of $\mathrm{HBx}$ in HBV-GN-induced renal EMT and to elucidate the potential underlying mechanisms.

For this purpose, we successfully transfected HBx plasmid into human renal proximal tubule epithelial cells (HK-2 cells), and determined that HBx promotes renal EMT through the activation of NF- $\mathrm{KB}$ phosphorylation, but not through that of other TGF- $\beta$ downstream factors. 


\section{Materials and methods}

HBx plasmid construction. HBx plasmid was provided by GeneCopoeia (Guangzhou, China). Full-length HBx was PCR-amplified from the p1.2II plasmid (HBV adr genome). The forward primer was 5'-GCGGTAGGCGTGTACGGT-3 and the reverse primer was 5'-GTGGCACCTTCCAGGGTC-3'. These were synthesized and inserted into the pEZ-M09 vector GeneCopoeia). An empty pEZ-M09 was used as a control. The PCR amplification protocol consisted of an initial 4-min denaturation at $94^{\circ} \mathrm{C}, 25$ cycles of denaturation at $94^{\circ} \mathrm{C}(1 \mathrm{~min}$ each), annealing at $60^{\circ} \mathrm{C}$ for $1 \mathrm{~min}$, extension at $72^{\circ} \mathrm{C}$ for $1 \mathrm{~min}$ and a final extension at $72^{\circ} \mathrm{C}$ for $10 \mathrm{~min}$. All ligated vectors were confirmed by sequence analysis. The stable selection marker was neomycin.

Cell culture and treatment. HK-2 cells (a kind gift from Dr Huiyao Lan, Li Ka Shing Institute of Health Sciences, Department of Chemical Pathology, The Chinese University of Hong Kong, Hong Kong, China) were cultured in DMEM-Ham's medium supplemented with $10 \%$ fetal bovine serum (FBS) (both from Gibco,Life Techologies, Grand Island,NY,USA). Cells at approximately $60 \%$ confluence were used for the in vitro experiments.

The HBx plasmid and empty plasmid (pEZ-M09) were mixed with Lipofectamine 2000 (Invitrogen, Carlsbad, CA, USA) separately and transfected into the cells following serum starvation for $12 \mathrm{~h}$ at various concentrations $(0,0.5,1.0,1.5$ and $2.0 \mu \mathrm{g} / \mathrm{ml}$ ). The cells were cultured in medium without FBS and harvested at different time points following transfection.

Reverse transcription-quantitative PCR (RT-qPCR). Total RNA was prepared from the HK-2 cells using TRIzol reagent, according to the manufacturer's instructions (Invitrogen). The RNA concentration was calculated using a Nanodrop ND1000 spectrophotometer (NanoDrop Technologies, Wilmington, DE, USA). Aliquots of each RNA extraction were reverse-transcribed simultaneously into cDNA using the One-Step RT-PCR kit (Takara, Tokyo, Japan) according to the manufacturer's instructions. Each qPCR reaction was performed in a total volume of $25 \mu 1$ in duplicate using the SYBR ${ }^{\circledR}$ Premix Ex Taq ${ }^{\mathrm{TM}}$ kit (Takara) and the Fast Real-Time PCR system 7500 (Applied Biosystems Inc., Foster City, CA, USA). The sequences of the primer pairs are listed in Table I. The thermal cycling conditions comprised $30 \mathrm{sec}$ at $95^{\circ} \mathrm{C}$, followed by $95^{\circ} \mathrm{C}$ for $5 \mathrm{sec}$ and $60^{\circ} \mathrm{C}$ for $34 \mathrm{sec}$ for 40 cycles with melting curve analysis. The relative quantification of each gene was calculated following normalization to GAPDH mRNA using the $2^{-\triangle \Delta C T}$ method.

Western blot analysis. Western blot analysis was performed as previously described (15). Briefly, total protein was extracted from the cells by lysis in $500 \mu$ of buffer containing Nonidet P-40 (10\%), Tris- $\mathrm{HCl}(25 \mathrm{mM}), \mathrm{NaCl}(150 \mathrm{mM})$, ethylenediaminetetraacetic acid (EDTA) $(10 \mathrm{mM})$ and a 1:50 dilution of a protease inhibitor cocktail (Sigma, St. Louis, MO, USA) for $30 \mathrm{~min}$ on ice. The cell lysates were centrifuged at $12,000 \mathrm{x} \mathrm{g}$ for $15 \mathrm{~min}\left(4^{\circ} \mathrm{C}\right)$. Cell lysates were heated at $95^{\circ} \mathrm{C}$ and separated on sodium dodecyl sulfate-polyacrylamide gel electrophoresis (SDS-PAGE) gels. Transferred membranes were immunoblotted with the following primary antibodies, respectively: anti-E-cadherin (610181; BD Biosciences, Franklin
Table I. The sequences of the primer pairs used for RT-PCR.

Primer Sequence

Human E-cadherin

Forward 5'-CTCAGTGTTTGCTCGGCGTTTGC-3'

Reverse 5'-GCTCTGGGTTGGATTCAGAG-3'

Human collagen I

Forward 5'-ACGTCCTGGTGAAGTTGGTC-3'

Reverse 5'-ACCAGGGAAGCCTCTCTCTC-3'

Human $\alpha$-SMA

Forward 5'-CATCACCAACTGGGACGACATGGAA-3'

Reverse 5'-GCATAGCCCTCATAGATGGGGACATTG-3'

Human fibronectin

Forward 5'-TCCTTGCTGGTATCATGGCAG-3'

Reverse 5'-AGACCCAGGCTTCTCATACTTGA-3'

Human GAPDH

Forward 5'-GCTGGCGCTGAGTACGTCGTGGAGT-3

Reverse 5'-CACAGTCTTCTGGGTGGCAGTGATGG-3'

Lakes, NJ, USA), anti- $\alpha$-smooth muscle actin ( $\alpha$-SMA; A5228200), anti-fibronectin (F364B, Sigma), anti-HBx (ab235, Abcam, Cambridge, NK), anti-collagen I (234167; Calbiochem, San Diego, CA, USA); anti-neomycin (myc; \#2276), anti-phosphorylated NF-kB ((\#3033), and anti-NF-кB (\#3032); anti-p-Smad2 (\#9510), anti-p-Smad3 (\#9520), anti-Smad2 (\#5339), anti-Smad3 (\#9523), anti-p-p38 (\#4511), anti-p38 (\#8690), anti-p-PI3K (\#4228), antiPI3K (\#4249), anti-p-ERK (\#4370) and anti-ERK (\#9102) (all from Cell Signaling Technology Inc., Beverly, MA, USA).

Following extensive washing, the membranes were incubated with the secondary antibodies (anti-mouse IgG, \#7076 and anti-rabbit IgG, \#4414; Cell Signaling Technology Inc.). Immobilized antibodies were then detected using an Odyssey detector (LI-COR Biosciences, Lincoln, NE, USA).

Immunofluorescence staining. Immunofluorescence staining was performed as previously described (16). Briefly, the cells cultured on cover slips were fixed, permeabilized with $0.5 \%$ Triton $\mathrm{X}-100$, and incubated with the primary antibodies overnight at $4^{\circ} \mathrm{C}$, followed by incubation with secondary antibodies (anti-mouse IgG, \#7076; anti-rabbit IgG \#4414; Cell Signaling Technology Inc.) conjugated to Alexa Fluor 488 or 588 (Invitrogen). The cells were then counterstained with 4',6-diamidino-2-phenylindole (DAPI) to visualize the nuclei. Images were acquired using a confocal microscope (Olympus Corp., Tokyo, Japan).

Statistical analysis. Data are expressed as the means \pm SD. Comparisons between 2 groups were conducted using a two-tailed t-test. Comparisons between multiple groups was made using one-way ANOVA followed by the StudentNewman-Keuls test. A value of $\mathrm{p}<0.05$ was considered to indicate a statistically significant difference.

\section{Results}

$H B x$ gene is successfully expressed in HK-2 cells following transfection. We first examined whether the HBx plasmid was successfully transfected into the HK-2 cells. The levels of both 

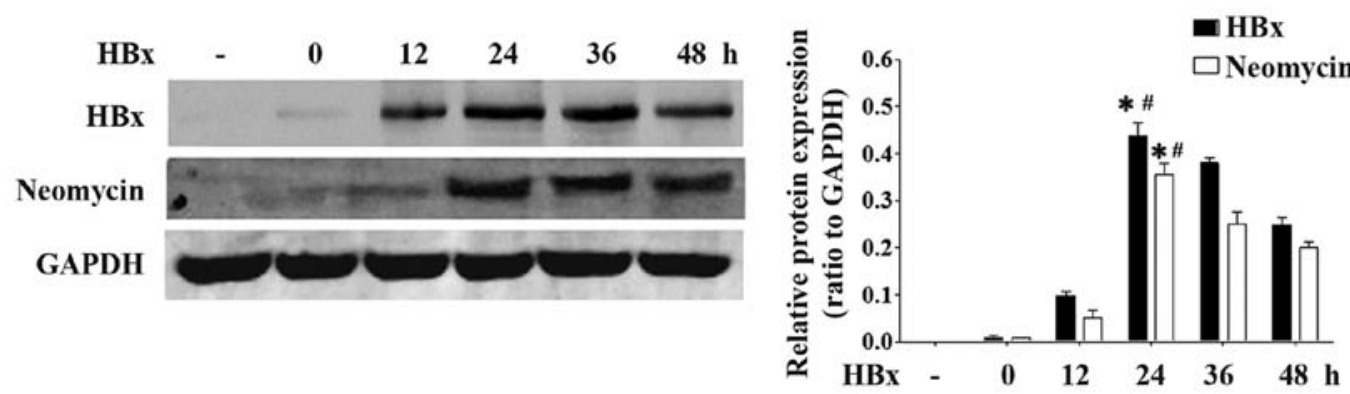

Figure 1. HBV X protein (HBx) plasmid was successfully transfected into HK2 cells. HK2 cells were co-transfected with empty pEZ-M09 or pEZ-M09-HBx plasmids. Cells were collected at $0,12,24,36$ and $48 \mathrm{~h}$ after transfection, and western blot analyses were performed with the antibodies against HBx and neomycin. Data are expressed as the means \pm SD of 3 independent experiments. ${ }^{*}$ p $<0.05$ vs. transfection with empty plasmid (HBx -); ${ }^{\# p}<0.05$ vs. 0 h (HBx 0$)$ post-transfection) (as shown by ANOVA).
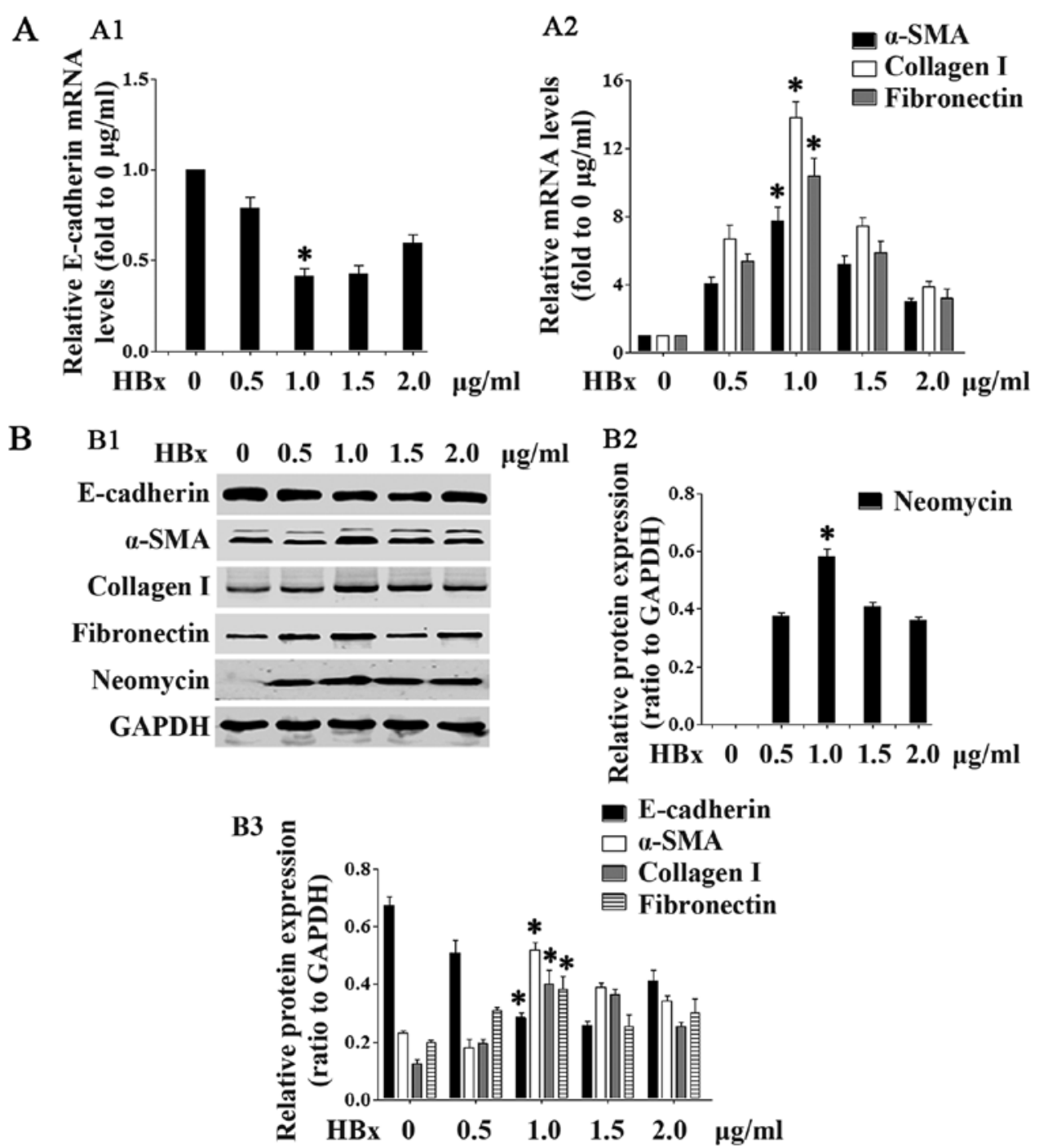

Figure 2. HBV X protein (HBx) protein promotes renal epithelial-mesenchymal transition (EMT). In concentration-dependent experiments, HK2 cells were transfected with the pEZ-M09-HBx plasmid at the concentrations of $0.5,1.0,1.5$ or $2.0 \mu \mathrm{g} / \mathrm{ml}$. (A) Cells were collected $24 \mathrm{~h}$ after transfection and RT-PCR was performed to detect the mRNA expression of (A1) E-cadherin, and (A2) $\alpha$-smooth muscle actin ( $\alpha$-SMA), collagen I and fibronectin. (B) Cells were collected $36 \mathrm{~h}$ after transfection, and western blot analyses were performed to detect the protein expression of neomycin, E-cadherin, $\alpha$-SMA, collagen I and fibronectin. (B1) Representative blots showing the expression of neomycin, E-cadherin, $\alpha$-SMA, collagen I and fibronectin. (B2) Quantification of neomycin. (B3) Quantification of E-cadherin, $\alpha$-SMA, collagen I and fibronectin. Data are expressed as the means \pm SD of 3 independent experiments. ${ }^{*} \mathrm{p}<0.05 \mathrm{vs} .0 \mu \mathrm{g} / \mathrm{ml}$ groups in (A1, A2, B2 and B3), as shown by ANOVA.

HBx (17 kDa) and neomycin (17 kDa) were markedly increased at $24 \mathrm{~h}$ following co-transfection with the HBx plasmid (Fig. 1).
These data suggested that the HBx plasmid was successfully transfected into the HK-2 cells. 
A

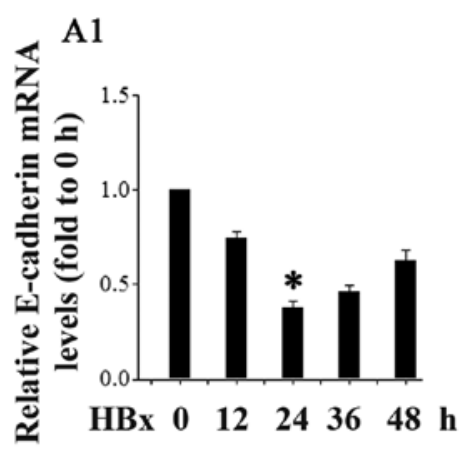

B

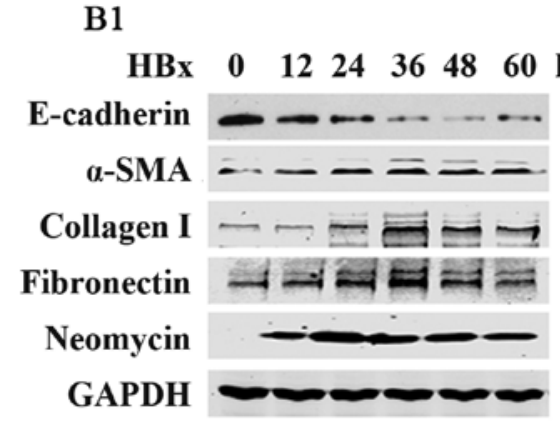

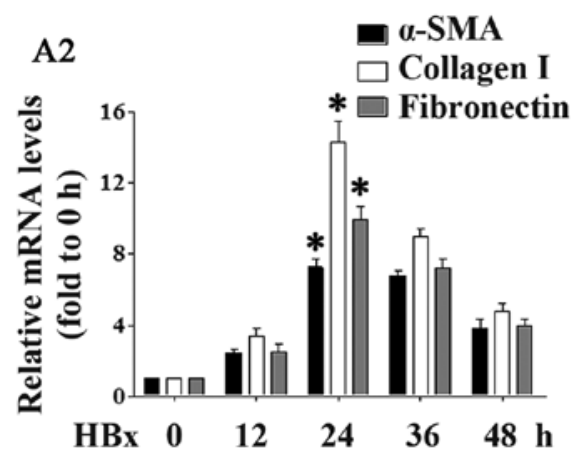

B2

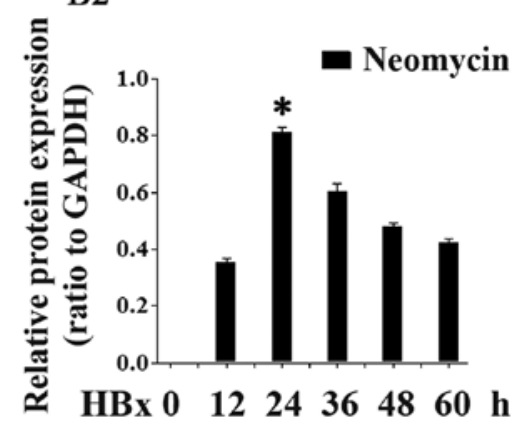

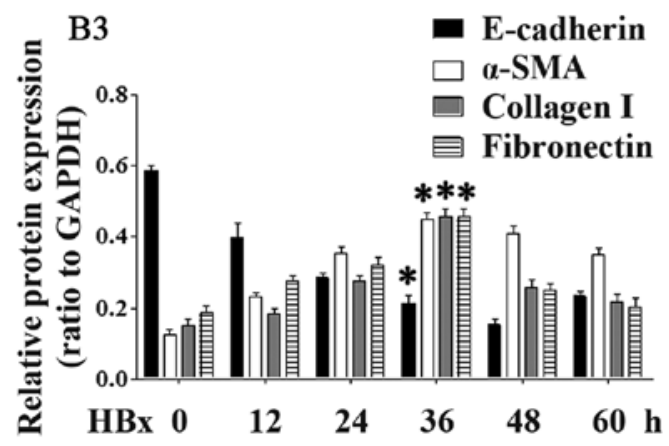

Figure 3. HBV X protein (HBx) promotes renal epithelial-mesenchymal transition (EMT). In time-dependent experiments, HK2 cells were transfected with the pEZ-M09-HBx plasmid (1.0 $\mu \mathrm{g} / \mathrm{ml})$ for the indicated periods of time. (A) Cells were collected and RT-PCR was performed to detect the mRNA expression of (A1) E-cadherin, and (A2) $\alpha$-smooth muscle actin ( $\alpha$-SMA), collagen I and fibronectin. (B) Cells were collected and western blot analyses were performed to detect the protein expression of neomycin, E-cadherin, $\alpha$-SMA, collagen I and fibronectin. (B1) Representative blots showing the expression of neomycin, E-cadherin, $\alpha$-SMA, collagen I and fibronectin. (B2) Quantification of neomycin. (B3) Quantification of E-cadherin, $\alpha$-SMA, collagen I and fibronectin. Data are expressed as the means $\pm \mathrm{SD}$ of 3 independent experiments. ${ }^{*} \mathrm{p}<0.05$ vs. $0 \mathrm{~h}$ groups in (A1, A2, B2 and B3), as shown by ANOVA.

HBx induces renal EMT. We then examined whether HBx affects EMT-related gene expression. As shown in Figs. 2 and 3, transfection with the lower concentrations $(0.5-1.0 \mu \mathrm{g} /$ $\mathrm{ml}$; Fig. 2) of the HBx plasmid and at the earlier time points (12 and $24 \mathrm{~h}$; Fig. 3) downregulated E-cadherin mRNA and protein expression in the HK-2 cells in a concentration- and time-dependent manner. Statistical significance was reached at the concentration of $1.0 \mu \mathrm{g} / \mathrm{ml}$ and at the $24-\mathrm{h}$ time point. Transfection with the higher concentrations $(1.5$ and $2.0 \mu \mathrm{g} / \mathrm{ml})$ of $\mathrm{HBx}$ and at the later time points (36 and $48 \mathrm{~h}$ ) slightly increased E-cadherin expression. At the same time, transfection with the HBx plasmid upregulated the mRNA and protein expression of $\alpha$-SMA, collagen I and fibronectin in a concentration- and time-dependent manner, again at the lower concentrations (Fig. 2) and earlier time points (Fig. 3). Statistical significance was reached at the concentration of $1.0 \mu \mathrm{g} / \mathrm{ml}$ and at the 24-h time point. At the higher concentrations and later time points, there was a slight decrease in the levels of $\alpha$-SMA, collagen I and fibronectin (Figs. 2 and 3).

As shown by confocal immunofluorescence microscopy, transfection with the HBx plasmid induced complete EMT in the HK-2 cells (as evidenced by the loss of E-cadherin expression, and the strong expression of $\alpha$-SMA and fibronectin) (Fig. 4).

HBx increases $N F-\kappa B$ phosphorylation. We then examined the potential molecular mechanisms responsible for the effects of $\mathrm{HBx}$ in renal fibrosis. Given the critical role of $\mathrm{NF}-\mathrm{\kappa B}$ activation in renal fibrosis, we hypothesized that HBx may be able to affect the phosphorylation of NF- $\kappa \mathrm{B}$. As shown in Fig. 5, transfection with $\mathrm{HBx}$ at the lower concentrations (0.5-1.0 $\mu \mathrm{g} / \mathrm{ml}$; Fig. 5A) and at the earlier time points (6-12 h; Fig. 5B) increased NF- $\kappa$ B phosphorylation in a concentration- and time-dependent manner. Statistical significance was reached at the concentration of $1.0 \mu \mathrm{g} / \mathrm{ml}$ and at the $12-\mathrm{h}$ time point. At the higher concentra- 

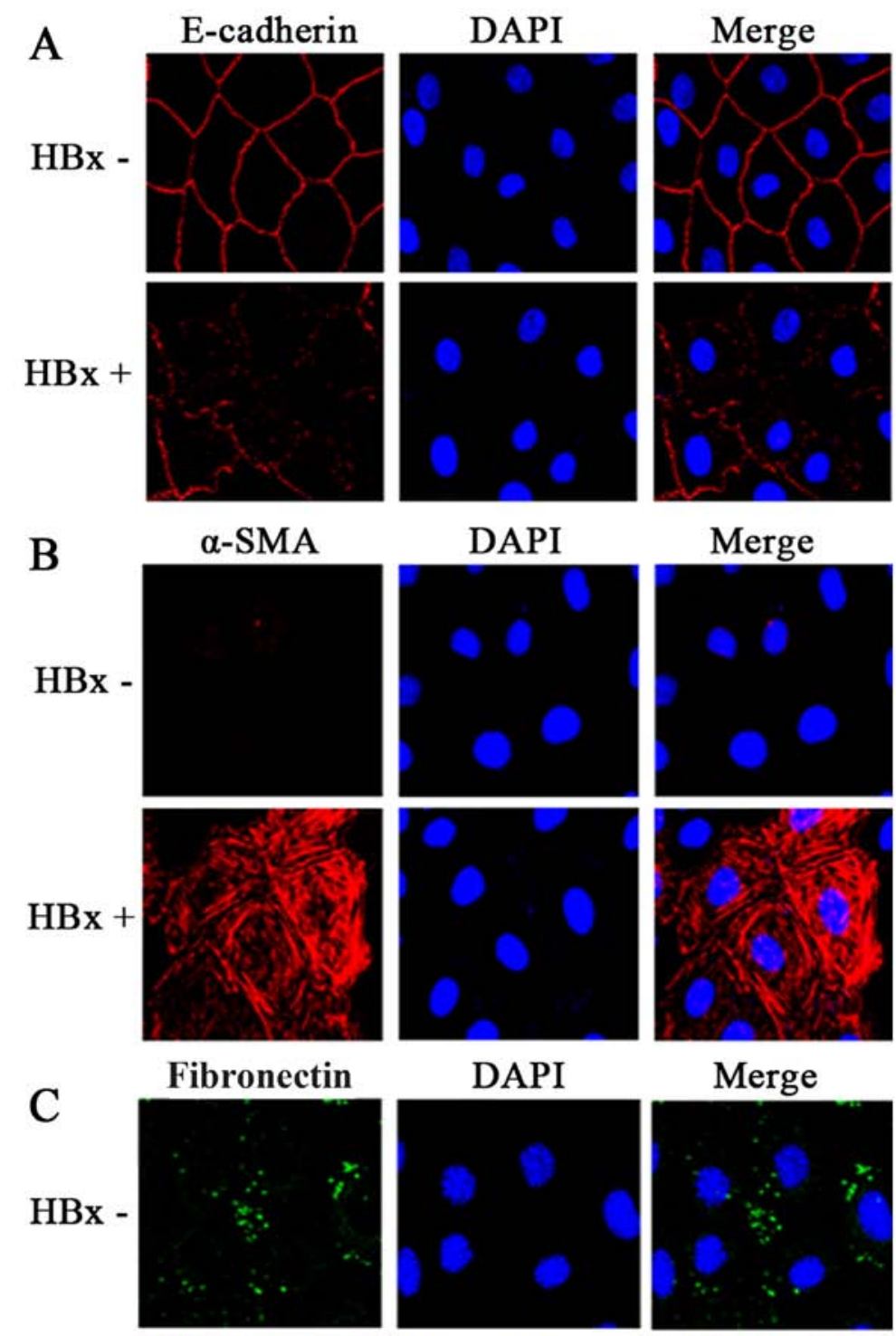

\section{Merge}

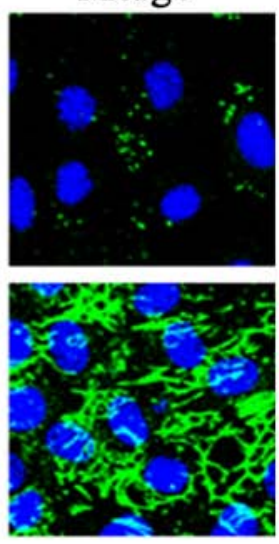

Figure 4. Immunofluorescence staining of E-cadherin, $\alpha$-smooth muscle actin $(\alpha$-SMA), collagen I, and fibronectin. HK2 cells were transfected with the empty pEZ-M09 (HBx -) or pEZ-M09-HBV X protein ( $\mathrm{HBx}+$ ) plasmids $(1.0 \mu \mathrm{g} / \mathrm{ml})$ for $36 \mathrm{~h}$. Cells were collected and immunofluorescence staining was performed to detect the protein expression of (A) E-cadherin, (B) $\alpha$-SMA and (C) fibronectin.

tions $(1.5-2.0 \mu \mathrm{g} / \mathrm{ml})$ and later time points $(18-36 \mathrm{~h})$, there was a slight decrease in NF- $\mathrm{KB}$ phosphorylation.

HBx does not affect TGF- $\beta 1$-associated Smad2, Smad3, p38, PI3K or ERK phosphorylation. We further examined whether $\mathrm{HBx}$ affects the other typical phosphorylation-associated signaling pathways, such as Smad2, Smad3, p38, PI3K and ERK. As shown in Fig. 6, HBx did affect Smad2 or Smad3 phosphorylation in the HK-2 cells. No significant differences were observed at any of the concentrations of HBx (Fig. 6A) or at any time point (Fig. 6B). Furthermore, as shown in Fig. 7, $\mathrm{HBx}$ was also unable to affect the phosphorylation of $\mathrm{p} 38$, PI3K or ERK, at any of the concentrations of HBx (Fig. 7A) or at any time point (Fig. 7B). These data suggested that HBx did not affect the phosphorylation of associated signaling pathways.

\section{Discussion}

In the present study, we demonstrated that $\mathrm{HBx}$, a $17-\mathrm{kDa}$ protein, significantly promoted renal EMT in renal HK-2 cells. Furthermore, HBx may promote renal EMT by increasing the phosphorylation of NF- $\mathrm{KB}$.

HBV-GN has been recognized as the most prevalent extra-hepatic manifestation caused by HBV infection (1-4). Its 

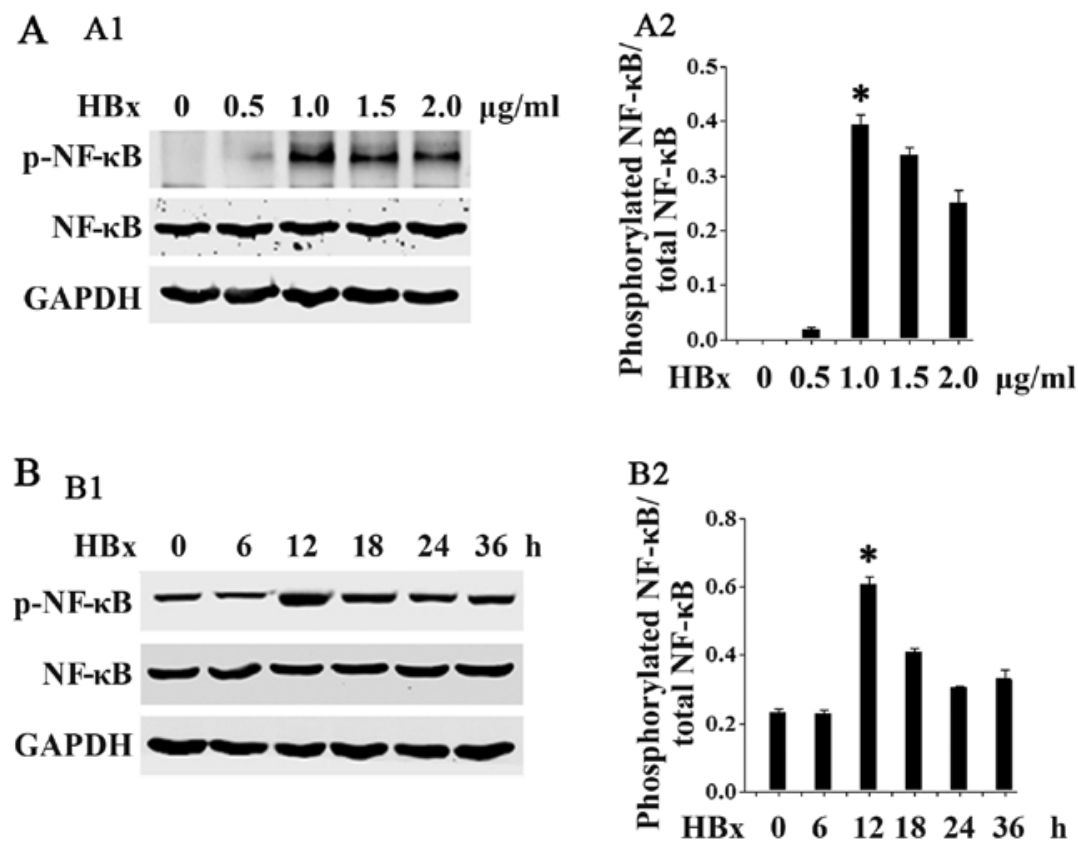

Figure 5. HBV X protein (HBx) increases nuclear factor- $\mathrm{kB}(\mathrm{NF}-\mathrm{\kappa B})$ phoshorylation. (A) HK2 cells were transfected with the pEZ-M09-HBx plasmid at the concentrations of $0.5,1.0,1.5$, or $2.0 \mu \mathrm{g} / \mathrm{ml}$. Cells were collected and western blot analyses were performed to detect the phosphorylation of NF- $\mathrm{kB}$ and total NF-kB. (B) HK2 cells were transfected with the pEZ-M09-HBx plasmid $(1.0 \mu \mathrm{g} / \mathrm{ml})$ for 6, 12, 18, 24 or $36 \mathrm{~h}$. Cells were collected and western blot analyses were

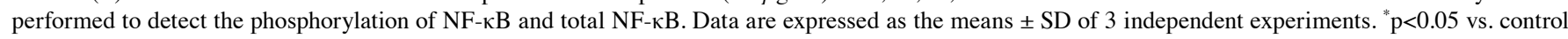
groups in (A2 and B2), as shown by ANOVA.

A A1

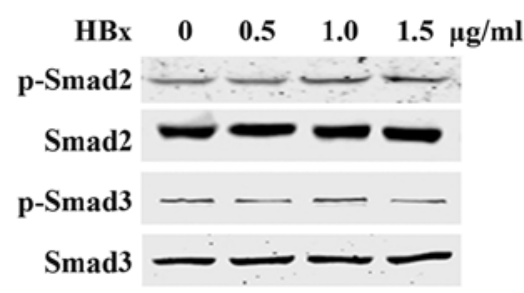

B

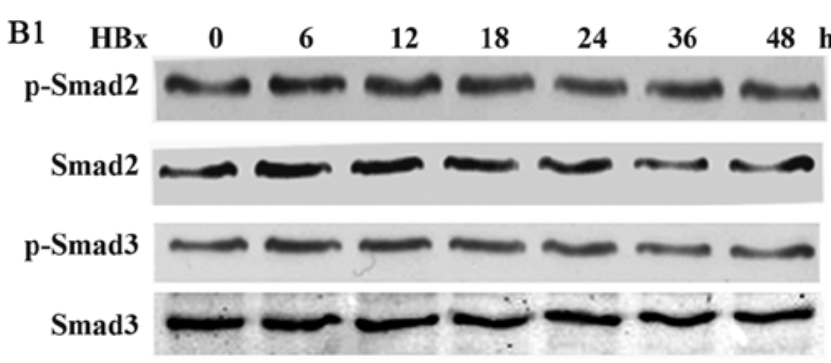

A2
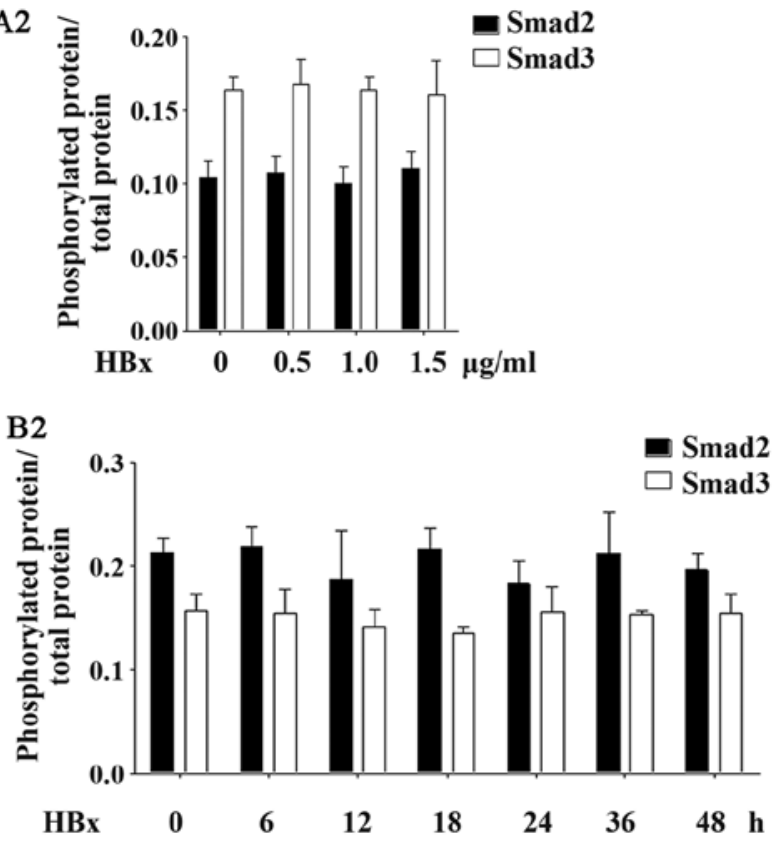

Figure 6. HBV X protein (HBx) does not affect Smad2 or Smad3 phoshorylation. (A) HK2 cells were transfected with the pEZ-M09-HBx plasmid at the concentrations of $0.5,1.0$ or $1.5 \mu \mathrm{g} / \mathrm{ml}$. Cells were collected and western blot analyses were performed to detect the levels of phosphorylated Smad2, total Smad2, phosphorylated Smad3 and total Smad3. (B) HK2 cells were transfected with the pEZ-M09-HBx plasmid (1.0 $\mu \mathrm{g} / \mathrm{ml})$ for 6, 12 , 18, 24, 36 or 48 h. Cells were collected and western blot analyses were performed to detect the levels of phosphorylated Smad2, total Smad2, phosphorylated Smad3 and total Smad3. Data are expressed as the means $\pm \mathrm{SD}$ of 3 independent experiments.

pathogenesis has not yet been completely clarified. HBV-DNA, covalently closed circular DNA (ccDNA) and even complete viral particles $(17,18)$ have been found in the kidneys of patients with HBV-GN, supporting the view that HBV can directly infect the kidneys and in situ reproduction to cause diseases. Over the years, research has focused on the existence and significance of
HBV-related nucleic acid molecules in nephridial tissue, such as $\mathrm{HBeAg}$, HBsAg and HBcAg (19-23). Recently, HBx was detected in renal tissues, mainly in tubular epithelial cells from patients with HBV-GN (5). In this study, we showed that HBx was highly expressed in HK-2 cells following transfection with HBx plasmid. 

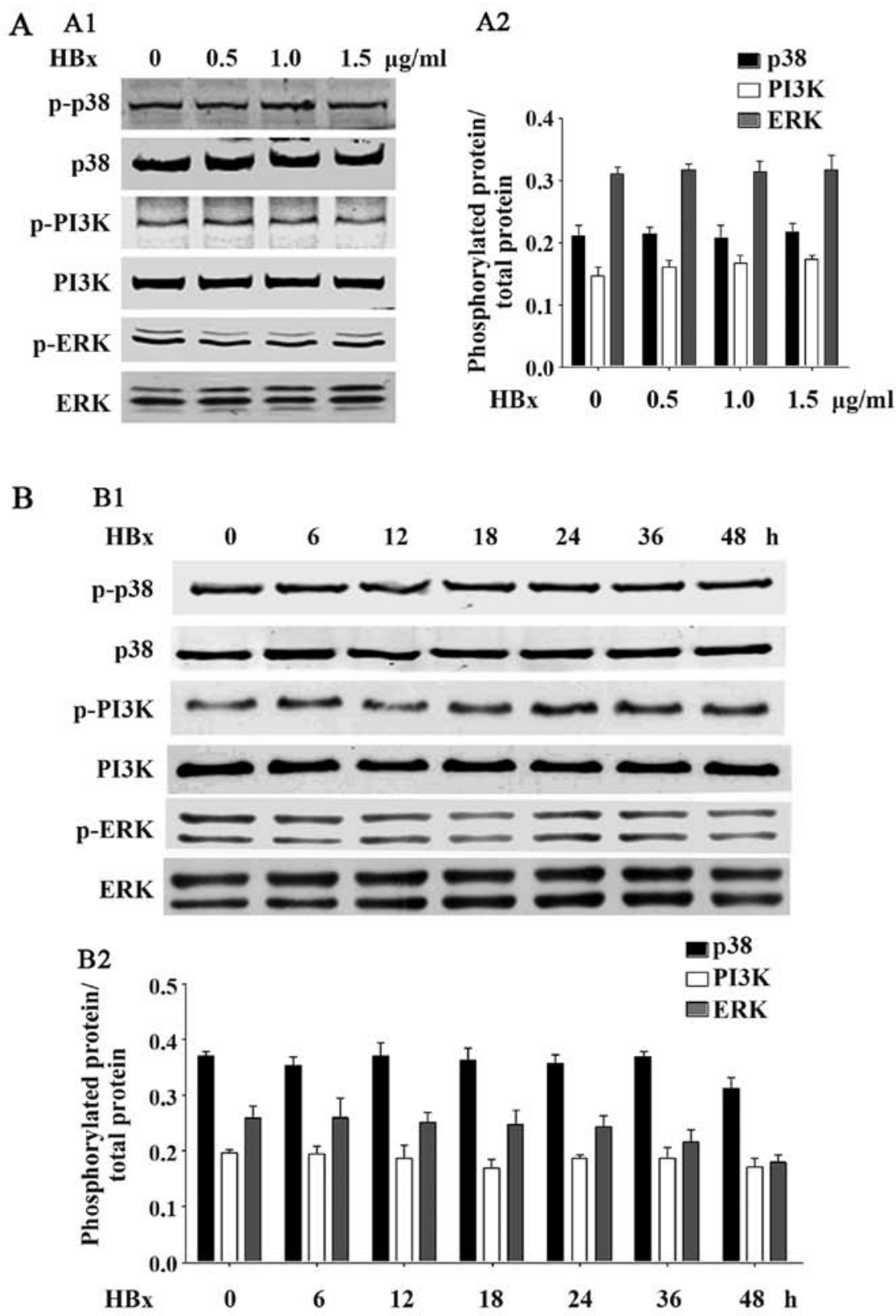

Figure 7. HBV X protein (HBx) protein does not affect p38, PI3K or ERK phoshorylation. (A) HK2 cells were transfected with the pEZ-M09-HBx plasmid at the dose of $0.5,1.0$ or $1.5 \mu \mathrm{g} / \mathrm{ml}$, respectively. Cells were collected and western blot analyses were performed to detect the levels of phosphorylation of phosphorylated p38, total p38, phosphorylated PI3K, total PI3K, phosphorylated ERK and total ERK. (B) HK2 cells were transfected with the pEZ-M09-HBx plasmid $(1.0 \mu \mathrm{g} / \mathrm{ml})$ for $6,12,18,24,36$ or $48 \mathrm{~h}$. Cells were collected and western blot analyses were performed to detect the levels of phosphorylated p38, total p38, phosphorylated PI3K, total PI3K, phosphorylated ERK and total ERK. Data are expressed as the means \pm SD of 3 independent experiments.

In liver cells, $\mathrm{HBx}$ is the most important determinant of viral pathogenesis, and it can modulate the transcriptional activation of AP-1 and NF- $\kappa \mathrm{B}(8,24)$, activate the Ras/Raf/ERKs, PI3K-Akt and JAK/STAT signaling pathways (7), promote cellular proliferation (25), affect apoptosis (26) and enhance the invasive potential (27) of infected cells. However, the influence of HBx in renal cells remains far from being completely understood. Renal fibrosis, characterized by massive interstitial myofibroblast activation and excessive matrix protein accumulation, is the final common pathway of virtually all types of progressive chronic kidney disease (CKD), leading to end stage renal disease (ESRD) (28). HBV-GN plays a critical role in the progression of CKD. Thus, we were wished to determine whether HBx plays a role in renal fibrosis. The present study demonstrated that co-transfection with HBx plasmid markedly downregulated E-cadherin mRNA and protein expression, and upregulated $\alpha$-SMA, collagen I, and fibronectin expression at the same time, suggesting that HBx promotes renal EMT. Although it has been demonstrated that the major cell component that produces extracellular matrix in unilateral ureteral obstruction is interstitial myofibroblasts (29), the contribution of tubular epithelial cell injury to ECM accumulation in fibrotic kidneys cannot be excluded (30).

Clippinger et al (8) successively researched the location of $\mathrm{HBx}$ protein in the mitochondrion and its influence on liver cell apoptosis. As a result, it was found that in liver cells, the function of $\mathrm{HBx}$ in apoptosis was mainly dependent on the $\mathrm{NF}-\kappa \mathrm{B}$ signaling pathway. Considering the imperative role 
of NF- $\mathrm{KB}$ in mediating renal EMT $(31,32)$, in this study, we examined the effects of HBx on NF- $\mathrm{kB}$ signaling. Indeed, our findings demonstrated that HBx markedly increased NF- $\kappa \mathrm{B}$ phosphorylation in the HK-2 cells, in a concentration- and time-dependent manner (at the lower concentrations and earlier time points). These data suggest that $\mathrm{HBx}$ may promote renal EMT through the NF- $\kappa B$ pathway. As the TGF- $\beta 1$ signaling has been recognized as a typical pathway in renal fibrosis and EMT, we also examined the effects of HBx on TGF- $\beta 1$-related signaling. Of note, co-transfection with the HBx plasmid did not affect the phosphorylation of Smad2, Smad3, p38, ERK or PI3K, suggesting that $\mathrm{HBx}$ may selectively promote NF-kB phosphorylation.

Therefore, as there is still no well-used animal model of HBV-GN, we could not confirm these results in animal experiments. Further studies are warranted using other types of renal cells, as well as animal models.

In conclusion, this study demonstrated that the activation of the NF- $\mathrm{KB}$ signaling pathway and changes in the levels of EMT-associated genes are involved in the process of EMT in HK-2 cells induced by HBx. These findings demonstrate that $\mathrm{HBx}$ may promote renal EMT through the activation of NF- $\mathrm{KB}$. Since an immortalized cell strain was used as the object of investigation in the present study, it is necessary to conduct further research in order to fully confirm our findings.

\section{Acknowledgements}

This study was supported by a grant from the Nanfang Hospital Foundation, Southern Medical University (no. 2012C08) to J.A.

\section{References}

1. Yi Z, Jie YW and Nan Z: The efficacy of anti-viral therapy on hepatitis B virus-associated glomerulonephritis: A systematic review and meta-analysis. Ann Hepatol 10: 165-173, 2011.

2. Abbas NA, Pitt MA, Green AT and Solomon LR: Successful treatment of hepatitis B virus (HBV)-associated membranoproliferative glomerulonephritis (MPGN) with $\alpha$ interferon. Nephrol Dial Transplant 14: 1272-1275, 1999.

3. Looi LM and Prathap K: Hepatitis B virus surface antigen in glomerular immune complex deposits of patients with systemic lupus erythematosus. Histopathology 6: 141-147, 1982.

4. Khaira A, Upadhyay BK, Sharma A, Das P, Mahajan S, Makhariya G, Dinda AK, Agarwal SK and Tiwari SC: Hepatitis B virus associated focal and segmental glomerular sclerosis: Report of two cases and review of literature. Clin Exp Nephrol 13: 373-377, 2009.

5. Zhou Y, Zhu N, Wang X, Wang L, Gu LJ and Yuan WJ: The role of the toll-like receptor TLR4 in hepatitis B virus-associated glomerulonephritis. Arch Virol 158: 425-433, 2013.

6. Lee WM: Hepatitis B virus infection. N Engl J Med 337: 1733-1745, 1997.

7. He P, Zhang D, Li H, Yang X, Li D, Zhai Y, Ma L and Feng G: Hepatitis B virus $\mathrm{X}$ protein modulates apoptosis in human renal proximal tubular epithelial cells by activating the JAK2/STAT3 signaling pathway. Int J Mol Med 31: 1017-1029, 2013.

8. Clippinger AJ, Gearhart TL and Bouchard MJ: Hepatitis B virus $\mathrm{X}$ protein modulates apoptosis in primary rat hepatocytes by regulating both NF-kappaB and the mitochondrial permeability transition pore. J Virol 83: 4718-4731, 2009.

9. Arbuthnot P, Capovilla A and Kew M: Putative role of hepatitis B virus X protein in hepatocarcinogenesis: Effects on apoptosis, DNA repair, mitogen-activated protein kinase and JAK/STAT pathways. J Gastroenterol Hepatol 15: 357-368, 2000.

10. Lee YI, Kang-Park S, Do SI and Lee YI: The hepatitis B virus-X protein activates a phosphatidylinositol 3-kinase-dependent survival signaling cascade. J Biol Chem 276: 16969-16977, 2001.

11. Kim H, Lee $\mathrm{H}$ and Yun Y: X-gene product of hepatitis B virus induces apoptosis in liver cells. J Biol Chem 273: 381-385, 1998.
12. Wang X, Zhou Y, Zhu N, Wang L, Gu LJ and Yuan WJ: The deposition of Notch1 in hepatitis B virus-associated nephropathy and its role in hepatitis B virus X protein-induced epithelialmesenchymal transdifferentiation and immunity disorder in renal tubular epithelial cells. J Viral Hepat 21: 734-743, 2014.

13. Schnaper HW, Hayashida T and Poncelet AC: It's a Smad world: Regulation of TGF- $\beta$ signaling in the kidney. J Am Soc Nephrol 13: 1126-1128, 2002.

14. Böttinger EP and Bitzer M: TGF- $\beta$ signaling in renal disease. J Am Soc Nephrol 13: 2600-2610, 2002.

15. Hao S, Shen H, Hou Y, Mars WM and Liu Y: tPA is a potent mitogen for renal interstitial fibroblasts: Role of betal integrin/ focal adhesion kinase signaling. Am J Pathol 177: 1164-1175, 2010.

16. Fritschy JM, Benke D, Mertens S, Oertel WH, Bachi T and Möhler H: Five subtypes of type A gamma-aminobutyric acid receptors identified in neurons by double and triple immunofluorescence staining with subunit-specific antibodies. Proc Natl Acad Sci USA 89: 6726-6730, 1992

17. He XY, Fang LJ, Zhang YE, Sheng FY, Zhang XR and Guo MY: In situ hybridization of hepatitis B DNA in hepatitis B-associated glomerulonephritis. Pediatr Nephrol 12: 117-120, 1998.

18. Zhou SD, Zhang YE, Guo MY, Fang LJ, Zhang XR, Zhang M, Wu Z, Lin SY and Liao LT: The study of the significance of the appearance of HbcAg in glomerulonephritis. Chin J Nephrol 11: 104-106, 1995.

19. Lin CY: Hepatitis B virus-associated membraneous nephropathy: Clinical features, immunological profiles and outcome. Nephron 55: 37-44, 1990.

20. Hirose H, Udo K, Kojima M, Takahashi Y, Miyakawa Y, Miyamoto K, Yoshizawa $\mathrm{H}$ and Mayumi M: Deposition of hepatitis B e antigen in membranous glomerulonephritis: Identification by $\mathrm{F}\left(\mathrm{ab}^{\prime}\right) 2$ fragments of monoclonal antibody. Kidney Int 26: 338-341, 1984

21. Hsu HC, Lin GH, Chang $\mathrm{MH}$ and Chen $\mathrm{CH}$ : Association of hepatitis B surface (HBs) antigenemia and membranous nephropathy in children in Taiwan. Clin Nephrol 20: 121-129, 1983.

22. Lai KN, Lai FM, Chan KW, Chow CB, Tong KL and Vallance-Owen J: The clinico-pathologic features of hepatitis B virus-associated glomerulonephritis. Q J Med 63: 323-333, 1987.

23. Knecht GL and Chisari FV: Reversibility of hepatitis B virusinduced glomerulonephritis and chronic active hepatitis after spontaneous clearance of serum hepatitis B surface antigen. Gastroenterology 75: 1152-1156, 1978.

24. Lee DH, Choi BH and Rho HM: The synergistic transactivation of the hepatitis B viral (HBV) pregenomic promoter by the E6 protein of human papillomavirus type 16 (HPV-16 E6) with HBV $\mathrm{X}$ protein was mediated through the AP1 site of E element in the enhancer I (EnI) in human liver cell. Biochem Biophys Res Commun 265: 62-66, 1999.

25. Ahuja R, Kapoor NR and Kumar V: The HBx oncoprotein of hepatitis B virus engages nucleophosmin to promote rDNA transcription and cellular proliferation. Biochim Biophys Acta 1853: 1783-1795, 2015.

26. Miao J, Chen GG, Chun SY and Lai PP: Hepatitis B virus $X$ protein induces apoptosis in hepatoma cells through inhibiting Bcl-xL expression. Cancer Lett 236: 115-124, 2006.

27. Liu Y, Tong Z, Li T, Chen Q, Zhuo L, Li W, Wu RC and Yu C: Hepatitis B virus $X$ protein stabilizes amplified in breast cancer 1 protein and cooperates with it to promote human hepatocellular carcinoma cell invasiveness. Hepatology 56: 1015-1024, 2012.

28. Zeisberg M and Neilson EG: Mechanisms of tubulointerstitial fibrosis. J Am Soc Nephrol 21: 1819-1834, 2010.

29. Grande MT and López-Novoa JM: Fibroblast activation and myofibroblast generation in obstructive nephropathy. Nat Rev Nephrol 5: 319-328, 2009.

30. Sutaria PM, Ohebshalom M, McCaffrey TA, Vaughan ED Jr and Felsen D: Transforming growth factor- $\beta$ receptor types I and II are expressed in renal tubules and are increased after chronic unilateral ureteral obstruction. Life Sci 62: 1965-1972, 1998.

31. Huber MA, Azoitei N, Baumann B, Grünert S, Sommer A, Pehamberger $\mathrm{H}$, Kraut $\mathrm{N}$, Beug $\mathrm{H}$ and Wirth T: NF-kappaB is essential for epithelial-mesenchymal transition and metastasis in a model of breast cancer progression. J Clin Invest 114: 569-581, 2004.

32. Maier HJ, Schmidt-Strassburger U, Huber MA, Wiedemann EM, Beug $\mathrm{H}$ and Wirth T: NF-kappaB promotes epithelialmesenchymal transition, migration and invasion of pancreatic carcinoma cells. Cancer Lett 295: 214-228, 2010. 